\title{
A Review on Decision Support System in Smart Farming
}

\author{
Mr. Muqueet ur Rehman, Dr. Sachin S. Agrawal, Dr. P. M. Jawandhiya
}

\begin{abstract}
The new smart era is based on science and technology that has changed the way of industrial operation. The traditional way of managing the heavy task and decision-making capabilities which mostly rely on the man-power system is now transforming with the advancement of computer and IoT technology in various domains. Day by day the new inventions are carried in the agriculture sector. A new way of farming with the implementation of technology is increasing crop production, monitoring, and irrigation techniques. This increase in crop production with limited farmland is playing a vital role in the needs of the growing population. To achieve this the decision support system can be integrated with the IoT which will give precise decisions of crop production based on the agriculture site. This article focuses on an IoT Based Smart Farming using Decision Support System project for crop prediction and management. The soil sensors based on soil samples provide the data regarding soil moisture, $\mathrm{PH}$ value, temperature, and humidity. These data are feed as input to the system via GSM/GPRS module and provide output as predicted crop after the analysis. All the data are stored on the server and can be managed by the user interface as a webpage. This research work will give farmers a new decision making for their farm based on real-time data which surely can reduce their efforts and economic crises.
\end{abstract}

Index Terms-About four key words or phrases in alphabetical order, separated by commas.

\section{INTRODUCTION}

Agriculture is one of the most important aspects that produce our food, clothing, and many more materials which are essential needs for our lives. As in recent decade's farmers have been suffering from many problems due to unpredicted climate change that can be forecast but cannot be right all the time and also due to improper crop production quantity as well as quality. The crop production problems arise due to lack of soil testing facilities or due to unaware of the right decision for the crop. As soil fertility is the important factor of the soil it should be checked periodically that will leads to decide the use of fertilizers, irrigation required for better crop growth. while having limited farmland available and also the

Manuscript revised on July 19, 2020 and published on August 10, 2020 Mr. Muqueet ur Rehman, PLITMS, Buldana Maharashtra, India

Dr. Sachin S. Agrawal, COET, Akola Maharashtra, India

Dr. P. M. Jawandhiya, PLITMS, Buldana Maharashtra, India diminishing of the farmland it becomes a severe problem which solution has to determine which is as important as to sustain the world ever-growing population. The solution can be obtained with this new smart era of modern computing technique based on the Decision Support System integrated with the Internet of Things (IoT).

Three basic components of a DSS architecture are:

- database (or knowledge base data collection)

- model (actual system)

- user interface.

The users themselves are also important components of the structure.

Further DSS components may be classified as:

- Inputs: Factors, numbers, and things to analyze

- User learning and expertise: Inputs requiring hand-operated analysis by the user

- Outputs: Converted data from which DSS "decisions" are generated.

- Decisions/Results: Results generated by the DSS based on user tests.

A decision support system is a computer-based application that gathers, organizes, and analyzes data to help quality decision-making for management, operations, and planning. [9] The DSS can be totally computerized or powered by humans. In some cases, the DSS may be a combination of both. This system analyzes information and actually make decisions for the user. A domain of DSS application, concepts, techniques, and principles are in agricultural production, marketing for sustainable development. For example, the Decision Support System for Agrotechnology Transfer (DSSAT) is a collection of computer programs for assuming agricultural crop growth.

It has been used in over 100 countries by agronomists for the evaluation of farming methods. Smart agriculture tries to make decisions for particular portions of farm fields. There are, however, many constraints to the successful selection of DSS in agriculture.

The objective of this research paper is to review an IoT based smart farming using a decision support system that provides decisions concerning the suitable crop prediction based on the various soil parameter such as soil moisture sensor, humidity sensor, temperature sensor, and $\mathrm{Ph}$ value sensor. 


\section{LITERATURE REVIEW}

The proper soil testing and the result obtained has its own importance in the selection of the crop for farming. However, the traditional soil testing method demands for a laboratory experiment that may lead to extra effort and time for the proper result. Therefore, it is supposed to be ineffective and inconvenient. There is a genuine need to overcome these issues with the new techniques of soil parameters measuring by different sensors and enhance the system with the clarity of decision-based on them.

Most of the research is made in the context of smart agriculture with a decision support system. Some of them is described below.

Dontrey Bourgeois, Suxia Cui, Pamela H. Obiomon, and Yonghui Wang have proposed a decision support system for precision farming. This system uses wireless sensor networks, high-performance computing, and data cloud that assist the farmer in making irrigation decisions by sending real-time data such as temperature and humidity to the farmer via the SMS system.[1]

Mr. Rohit M Bhekane, Dr. Udaykumar L Naik, has proposed an embedded decision support system for smart farming. This system is capable of data analysis of Wireless Sensor Network (WSN) based temperature, humidity, soil moisture on the fields that are uploaded onto IoT site ThingSpeak. It works on IEEE 802.15.4 protocol and provides $2.4 \mathrm{GHz}$ ZigBee connectivity which supports connectivity around 100 meters.[2]

Dr. S. L. Satarkar, Dr. S. S. Agrawal, Prof. S. C. Makwana, and Prof. P. V. Joshi has proposed a system to overcome the issue of the traditional system of farming. It depends on IoT, computer analysis, Internet and improved communication, expert systems, and sensors that provide great help to the farmers in the monitoring and management of farm and resources. [3]

Carlos Cambra Baseca and Sandra Sendra in his article define a system named as smart decision system for digital farming. The paper described a complete implementation of a decision support system prototype, which automatically gets rules from data, thereby providing the domain expert to select the resulting rule base. Besides, the system includes rules based on variable-rate irrigation (VRI). [4]

P. Uva Dharini, S. Monisha, K. Narrmadha, K. Saranya has proposed an IoT based system for the enhancement of the crop yield using decision support system The IoT devices are used in the system to provide an automated data capture solution from sensors. Raspberry pi is used as a connecting interface to a cloud server. The system includes IOT gateway \& Cube in Raspberry Pi and IoT server program Mobius provides API to develop mobile apps. The role of Mobius is to communicate with the Expert system and control actuators. Since the mobiles are used everywhere, mobile apps. [5]

\section{BENEFITS OF DSS FARMING}

This section focuses on the benefits of the decision support system in farming. [6]

- Decision support systems (DSS) for agriculture give information support to provide to the farmers' decision, by combining various forms of information required for growing crops.

- DSSs present information to the farmer about the soil properties and parameters also suggest the most relevant crop in their agriculture farm.

- A DSS can be of the simple form, such as software that shows the relevant crop recommended for excellent growth.

- Implementing the DSS in farming with advanced technology such as IoT can be reliable and provide real-time decisions. DSS can be extensible to the global perspective of the farming world.

- The wireless sensor network providing the climate change information and soil sensors can lead to the generation of automatic farm monitoring and management.

- Mobile technology can also be embedded in the DSS architecture for acquiring its easy use and reliability.

\section{Proposed System}

The proposed system consists of the four module which are control and monitor by the webpage. Every module is connected with the Arduino UNO along with the GSN/GPRS module which is responsible to establish the communication between the module and the webserver. The only purpose is to achieve the best and efficient solution for the crop decision by combining the real-time soil sensor and the Internet of Things. The Arduino UNO is used because the programming environment and its language is easy to understand even for people who have not programmed before and it is the best choice to be considered.

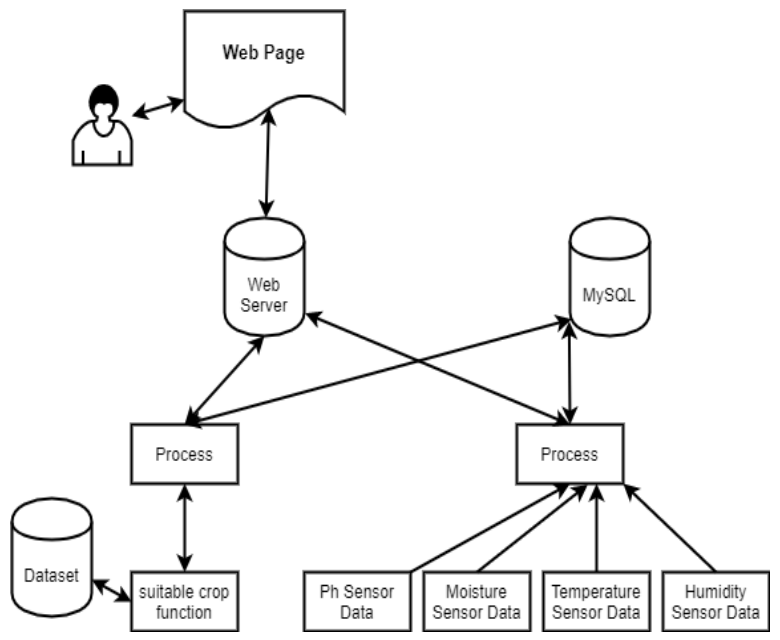

Figure 1 Structure of Proposed system

\section{A. First Module}

The first module is designed to take the number of readings from the soil sample to achieve best result as sensor cannot provide exact value at a time. The first module consists of the various sensors as follows: 
(1) Soil Moisture Sensor.

Soil Moisture Sensor FC28 consists of two probes thar are dipped into the soil to obtained the soil moisture level. It is simple and easy to use with Arduino board.

(2) Temperature \& Humidity Sensor.

Temperature and Humidity is measured with the help of the DHT11 sensor as it comes with factory calibrated and can be configure easily with Arduino board.

(3) Soil PH Sensor.

The Soil PH sensor also consist of two probes which are required to dipped in the soil to obtained the soil $\mathrm{PH}$ value. To obtain more accurate value add some water in the soil sample.

\section{B. Second Module}

The second module focuses on establishing the communication of the Arduino UNO with the webserver. The GPRS/GSM sim 900A module is used to upload the sensor value to the webserver. This SIM900A module operates with the help of AT command which enables it to make an HTTP request to communicate and receive the response from the server.

\section{Third Module}

The third module is the suitable crop function algorithm to which the transfer of the input from the various sensors is analyses and output is provided with the name of the crop suitable according to the soil tested. The algorithm for the design system works as follows below:

(1) Calculate the average value of each soil parameter received as input.

(2) Obtain list of suitable crops by $\mathrm{PH}$ value on the basis of average value calculated value in (1).

(3) Obtain list of suitable crops by Moisture value on the basis of average value calculated value in (1).

(4) Obtain list of suitable crops by Temperature value on the basis of average value calculated value in (1).

(5) Obtain list of suitable crops by Humidity value on the basis of average value calculated value in (1).

(6) Crop get determine by calculating the intersection of Step 2,3,4,5.

(7) Store all data in the respective database.

\section{Fourth Module}

The fourth module comprises the database and the webserver. The database used here is the MYSQL database which is used to store all the input data, dataset, and output. Dataset is nothing but the set of the related crop and their relative parameter to help in determining the crop suitable for the soil sample tested.

All the controlling and working is interfaced to the user via interactive and easy to use web pages.

\section{E. Work Flow}

A conclusion section is usually required. Although a conclusion may review the main points of the paper, do not replicate the abstract as the conclusion. A conclusion might elaborate on the importance of the work or suggest applications and extensions.

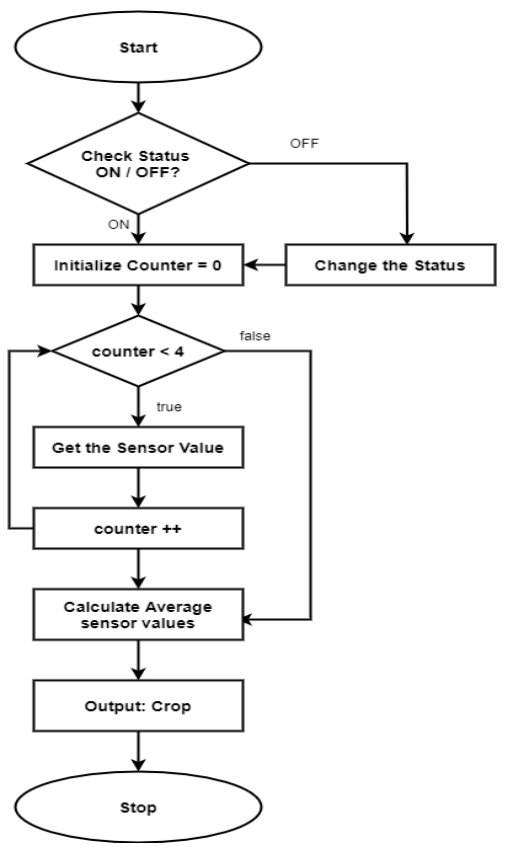

Figure 2 Work Flow of DSS System

\section{RESULT AND EXPERIMENTS}

This section describes the result of the decision support system. Experimental setup for all modules consists of various sensors and modules all are connected successfully. And result is obtained in the form of suitable crop.

Table 1. Crop table with respective parameter

\begin{tabular}{|l|l|l|l|l|}
\hline Crop & Temperature & Humidity & Moisture & PH Value \\
\hline Wheat & $12-25$ & $21-24$ & $21-24$ & $5.5-6.5$ \\
\hline Rice & $24-30$ & $21-37$ & $21-37$ & $5.5-7.0$ \\
\hline Orange & $12-37$ & $10-35$ & $10-37$ & $6.0-7.5$ \\
\hline Sugarcane & $20-27$ & $28-32$ & $28-32$ & $5.0-8.5$ \\
\hline Tomato & $15-32$ & $25-80$ & $25-80$ & $6.0-6.8$ \\
\hline Apple & $21-24$ & $20-25$ & $20-25$ & $5.5-6.5$ \\
\hline Cabbage & $15-30$ & $30-85$ & $40-80$ & $6.5-7.0$ \\
\hline Carrot & $18-26$ & $40-90$ & $75-85$ & $4.5-6.0$ \\
\hline Pumpkin & $21-32$ & $35-80$ & $50-70$ & $6.0-6.5$ \\
\hline Okra & $21-30$ & $45-75$ & $55-75$ & $6.5-7.0$ \\
\hline
\end{tabular}

The proposed decision support system in this report has been implemented to minimize the number of factors in the farming decision and soil parameter analysis with the help of modern technology and various sensors. This system provides the information with the real-time factors of the soil 
which depends on the environmental conditions also the soil sensor used to give their respective value. However, this system can be more effective if the above scenario is compared with the actual soil testing carried out by many different traditional methods. Also, the decision support is properly matched with the prior knowledge and experiments. Our system can provide the soil capabilities of producing the proper crop but there are many other factors of the soil such as soil nutrients which are further classified as basic, macro, micro, etc but sensors are not available or developed to measure it more efficiently. Many works are going to improve crop productivity all along with the different domains.

\section{LIMITATIONS AND FUTURE SCOPE}

This section describes the limitation and the future scope of the decision support system in agriculture using IoT as given below.

\section{A. Limitations}

Despite their views, soon DSSs have contributed very small to solve practical problems in crop security under real field conditions due to severe developed difficulties during their adoption and use. There are some of the limitations of using the decision support system with IoT in farming as listed below.

(1) There are some more parameter of the soil that play important role in the soil fertility known as nutrient they are further classified as micro. Macro and primary nutrient they are calculated only with experiment no sensor available for them to measure.

(2) The failure to adopt DSSs may be somewhat correlated to the gaps in farmers' knowledge of the human role and the tendency to overlook risk linked with management.

(3) Not all the soil macro nutrient, micro nutrient and primary nutrient can be sense by the sensor as these nutrients can only be calculated through chemical experiments.

\section{B. Future Scope}

In future, this system can be improved with the implementation of the upcoming sensors or devices and forming the expert decision support to formulate proper data set related to crops and soil. The improvement in the decision support system and soil testing with the help of the sensors surely leads to the change in face of farming by overcoming the issues. This system can also be compressed into one single device that can communicate with the remote server with the help of the Internet and operable on the battery. Also, the research can be concentrated on enhancing the farming techniques with the help of the mobile devices to monitor and control the farming activities.

\section{REFERENCES}

[1] Dontrey Bourgeois, Suxia Cui, Pamela H. Obiomon, Yonghui Wang "Development of a Decision Support System for Precision Agriculture" International Journal of Engineering Research \& Technology (IJERT) ISSN: 2278-0181 Vol. 4 Issue 10, October-2015.

[2] Mr. Rohit M Bhekane1, Dr. Udaykumar L Naik2 "EMBEDDED DECISION SUPPORT SYSTEM FOR SMART FARMING" International Research Journal of Engineering and Technology (IRJET) e-ISSN: 2395-0056 Volume:04 Issue:08|Aug-2017.

[3] Dr. S. L. Satarkar, Dr. S. S. Agrawal, Prof. S. C. Makwana, Prof. P. V. Joshi "Decision Support System for Smart Agriculture using IoT" International Journal of Scientific Research and Review ISSN No.: 2279-543X Volume 07, Issue 04, April 2019.

[4] Carlos Cambra Baseca, Sandra Sendra, Jaime Lloret, Jesus Tomas "Article A Smart Decision System for Digital Farming" https://www.mdpi.com/journal/agronomy Published: 27 April 2019.

[5] P. Uva Dharini, S. Monisha, K. Narrmadha, K. Saranya "IOT Based Decision Support System for Agriculture Yield Enhancements" International Journal of Recent Technology and Engineering (IJRTE) ISSN: 2277-3878, Volume-7 Issue-4S, November 2018.

[6] Panagiotis Kanatas, Ilias S. Travlos, Ioannis Gazoulis, Alexandros Tataridas, Anastasia Tsekoura and Nikolaos Antonopoulos Review on "Benefits and Limitations of Decision Support Systems (DSS) with a Special Emphasis on Weeds".

[7] Chaithra N T, Nagarathna ,NithiKumar "Measurable Nutrients and Available Sensors to Design a Soil Tester with Crop recommendation". IOSR Journal of Computer Engineering (IOSR-JCE) e-ISSN: 2278-0661, p-ISSN: 2278-8727, Volume 21, Issue 2, Ser. III (Mar - Apr 2019), PP 17-22.

\section{AUTHORS PROFILE}

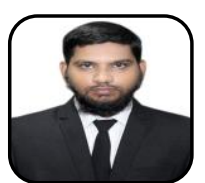

Mr. Muqueet ur Rehman, Student, Department of Computer Science \& Engineering, Pankaj Laddhad Institute of Technology and Management Studies Buldana, Maharashtra, India.

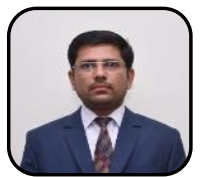

Dr. Sachin S. Agrawal, Associate Professor, Department of Computer Science \& Engineering, College of Engineering and Technology Akola, Maharashtra, India.

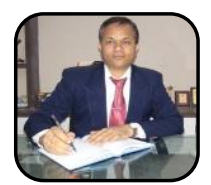

Dr. P. M. Jawandhiya Principal, Pankaj Laddhad Institute of Technology and Management Studies Buldana, Maharashtra, India. 